\title{
PV based standalone system performance enhancement using MPPT with PID controller
}

\author{
Pankaj Kumar Gupta ${ }^{1}$, \\ ${ }^{1}$ Assistant Professor, ABES Engineering College, Ghaziabad, India, pankaj681@rediffmail.com
}

\begin{abstract}
Alternative energy sources, such as solar energy and fuel cells, are desirable due to their pollution-free property. This paper covers a vast coverage of the maximum power point tracking (MPPT) techniques for photovoltaic (PV) power systems. Several publications report on different MPPT techniques for a PV system together with implementation. But, confusion lies while selecting a MPPT as every technique has its own merits and demerits. In this paper description and classification of the MPPT techniques is provided based on features like control variables, control strategies employed, circuitry used and practical/ commercial applications. The review in this paper is intended to find appropriate MPPT controller for designing an efficient PV systems for standalone and grid connected applications.

In this paper photovoltaic (PV) plant module is for compensating power demand for standalone system. The designed modules are connected to switch-mode power converters to enhance the power output in every environmental condition. This task is performed by an advanced incremental conductance MPPT algorithm, which provides a current or voltage reference to the converter.
\end{abstract}

Key words : Photovoltaic, Solar irradiations, Photovoltaic Array

\section{INTRODUCTION}

The solar radiation can be directly converted into electricity because of the photovoltaic (PV) effect but unfortunately similar to most of the so-called alternative sources, the cost of energy is substantially higher than that produced from fossil fuels. In spite of the phenomena of reflection and absorption of sunlight by the atmosphere, it is estimated that solar energy incident on the Earth's surface is on the order of ten thousand times greater than the world energy consumption. By the year 2030, the annual reduction rate of $\mathrm{CO} 2$ due to the usage of PV cells may be around $1 \mathrm{Gton} / \mathrm{year}$, which is equivalent to India's total emissions in 2004 or the emission of 300 coal plants [1]. According to experts, the energy obtained from PV cells will become the most important alternative renewable energy source until 2040 [2]. Because of the economical support, in the last years, there has been a proliferation of PV plants. The cost effectiveness of a PV plant for given environmental conditions basically depends on two aspects. The first is the technology employed to build the PV cells; the second is the configuration and the control algorithms implemented in power converters. It is well known that the low-frequency behavior of an array of PV modules can be represented by a current-voltage characteristic, while the dynamics can be neglected in most of the applications.

Despite all the advantages the efficiency of energy conversion is low, and the initial cost of implementation is high; thus, it is necessary to use techniques to extract the maximum power from these panels, in order to achieve maximum efficiency in operation. PV panels exhibits a unique operating point where nonlinear PV panel power characteristic power is maximized.The power varies with respect to solar irradiation and temperature, which make the extraction of maximum power a complex task, considering load variations. To overcome this problem, several methods for extracting the maximum power have been proposed [3]-[7]. Photovoltaic systems either supply power directly to an electrical equipment or feed energy into the public electricity grid. The electricity produced from solar PV array can be fed directly into the grid (grid-interactive mode) or can be used to meet the power demand of the off-grid loads (standalone mode). The present paper deals with both the issues of solar PV systems operating in standalone mode to provide power to domestic loads in locations wherein grid is not available and also to the grid connected system.

\section{STANDALONE SYSTEM}

In developing countries, where rural electrification is embryonic, the applications of photovoltaic (PV) systems are important. Extending power lines to rural areas is often not yet economical [2] hence stand-alone photovoltaic systems are one of the economical alternative in such remote areas which have no access to a utility grid. These systems are providing reliable power for commercial, stand-alone, facility power, lighting, security lighting, transportation etc. [1].

In these PV stand-alone systems to extract the maximum power of the PV array, a series connection is made in between $\mathrm{dc}-\mathrm{dc}$ converter, PV array and the load or the energy storage element. In this series connection, the dc-dc converter always processes all power generated, the total efficiency of the PV system greatly depends on this dc-dc converter [3].

\section{A.SERIES CONNECTION OF THE MPPT}

The practical implementation of the MPPT algorithm is normally accomplished through a digital system, which uses a controller. The converteroperations are as a buck converter for the battery charger modeor as a boost converter when the battery must supply the $\operatorname{load}\left(R_{\mathrm{L}}\right)$ or when the load energy 
demand is higher than the energygenerated. In this paper the boost converter is used for compensating the higher load energy demand.

The boost operation mode is very useful because the energy generated at theMPP is not enough to supply the load. In the boost converters when a switch is turnedon an inductor $\mathrm{L}$ stores energy from the battery.

Inductor:The average inductor current in the boost operation is defined by (1), considering an efficiency equal to $\eta=90 \%$

$$
I_{L}=\frac{P}{V_{b} * \eta}
$$

A current ripple that is equal to $20 \%$ was considered in the inductance determination

$$
\Delta I=0.2 * I_{\mathrm{L}}
$$

The operation point defined is a duty cycle that is equal to $\mathrm{D}$, which is in order to obtain the desired load voltage .The inductance is calculated by

$$
L=\frac{V_{\text {in }} * D}{f * \Delta I}
$$

An inductance value that is equal to $100 \mathrm{mH}$ was utilized in the prototype.

Capacitor:A capacitor voltage ripple that is equal to $5 \%$ is adopted in the design of the filter capacitor

$$
\Delta V_{\mathrm{C}}=V_{o} * 0.05
$$

The capacitance is calculated by

$$
C=\frac{I_{c a p} * D}{f * \Delta V_{C}}
$$

The capacitor current is defined by

$$
I_{\text {cap }}=I_{c}+\frac{\Delta I}{2}
$$

A capacitor with $500 \mu \mathrm{F}$ is connected in parallel for the output capacitor implementation while also considering the equivalent series resistance. The operation of the proposed system is simulated with the implementation on SIMULINK/MATLAB prototype, which is shown in Fig. 1.The PV module utilized in the simulation model is the Kyocera KD135GX-LP with maximum power equal to 185 $\mathrm{W}$.

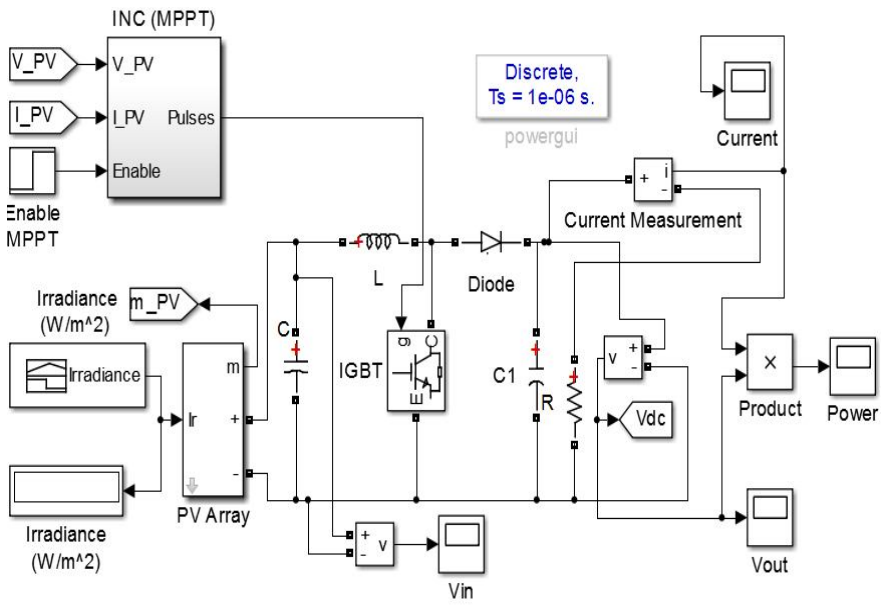

Fig. 1. Simulink diagram of PV array connection with Standalone System

\section{RESULT AND DISCUSSION}

The standalone systems designed here for low power applications in the range of $250 \mathrm{VA}$ to $1000 \mathrm{VA}$. The voltage levels of individual PV modules are as per the availability in the market $(12 \mathrm{~V}, 17 \mathrm{~V}$ and $36 \mathrm{~V})$. The voltage level of loads for this type of applications is of 12 to $48 \mathrm{~V}$. The standard voltage level of domestic loads in India is $230 \mathrm{~V}$. As a result voltage level of dc link of the dc-ac inverter that feeds these loads has to be maintained in the range of $360 \mathrm{~V}$ to $400 \mathrm{~V}$. Therefore the overall voltage gain of the intermediate dc-dc converter(s) which interfaces the PV array and the load needs to be designed for a voltage gain of around 9-12 [5]. The solar radiation and other meteorological parameters have been taken from the Solar Radiation Data Handbook [6]. The various parameters that have been used in this design are the PV module reference efficiency $\eta_{\mathrm{r}}=15 \%$, reference solar cell temperature $T_{1}=25^{\circ} \mathrm{C}$, standard solar intensity $=1000 \mathrm{~W} / \mathrm{m}^{2}$. In this case study the PV standalone system response to a step increase in irradiance at $1 \mathrm{sec}$ and load feeding over 0 to 5 seconds period is evaluated. The PV array specification and parameters are defined earlier in section 2 is employed. Fig. 2, 3,4 and 5 show the responses obtained for a step increase in irradiance (from 1 to $1.2 \mathrm{~kW} / \mathrm{m}^{2}$ (Fig.2), with $25^{\circ} \mathrm{C}$ ambient temperature), for fulfilling intention of providing sharp sweep in the input voltage. It can be observed from Fig. 3 that initially the PV system operates without MPPT from 0 to 0.4 secs. the MPPT applied after $0.4 \mathrm{sec}$ with corresponding current of about $3.25 \mathrm{~A}$ (at $1 \mathrm{~kW} / \mathrm{m}^{2}$ ) seen from the load side after $1 \mathrm{sec}$ the irradiance is step up to $1.2 \mathrm{~kW} / \mathrm{m}^{2}$ and current is increased to $3.6 \mathrm{~A}$. During the sudden application of MPPT and change in irradiance, a temporary overvoltage that arises prompts the controller to immediately start over-voltage control action. The resulting voltage overshoot is quickly damped and is limited to within $2 \%$ of the thresh hold value by the controller action [7].

Fig 4 shows that enabling the MPPT the voltage rises to $163 \mathrm{~V}$ and when irradiance increases at $1 \mathrm{sec}$ than voltage rises to $180 \mathrm{~V}$.Similarly when MPPT is active, power rises to 535 watts and when irradiance changes at $1 \mathrm{sec}$ the power rises to 640 watts as shown in fig. 5.The fig 6,7 and 8 shows the waveform of current, voltage and power with PI Controller. There is greater oscillation in current, voltage and power without PI Controller as compared to with PI Controller as shown.

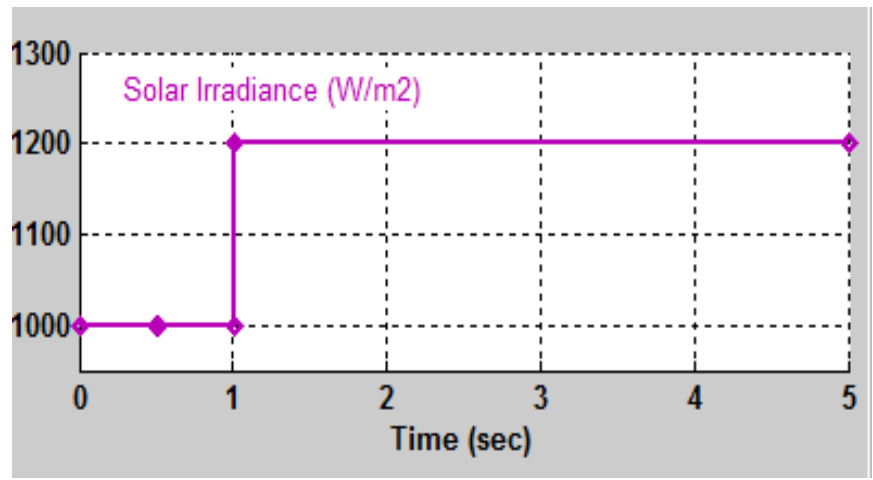

Fig. 2. Solar Irradiance applied to the system 


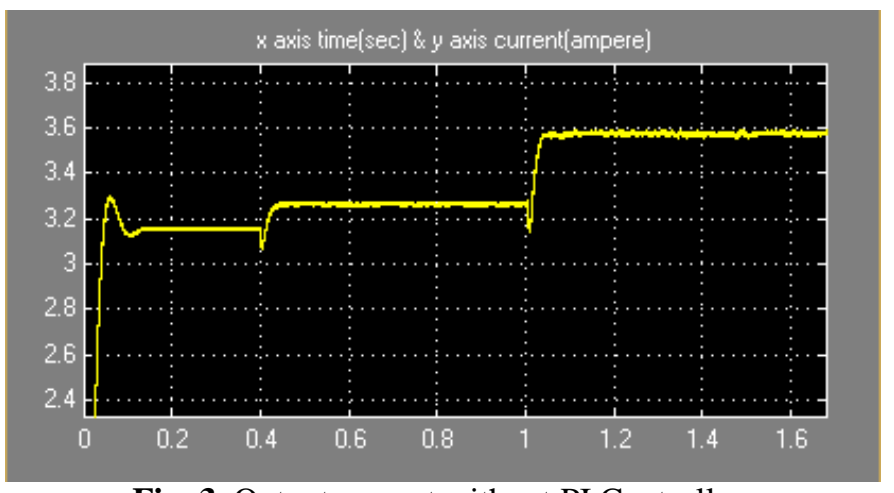

Fig. 3. Output current without PI Controller

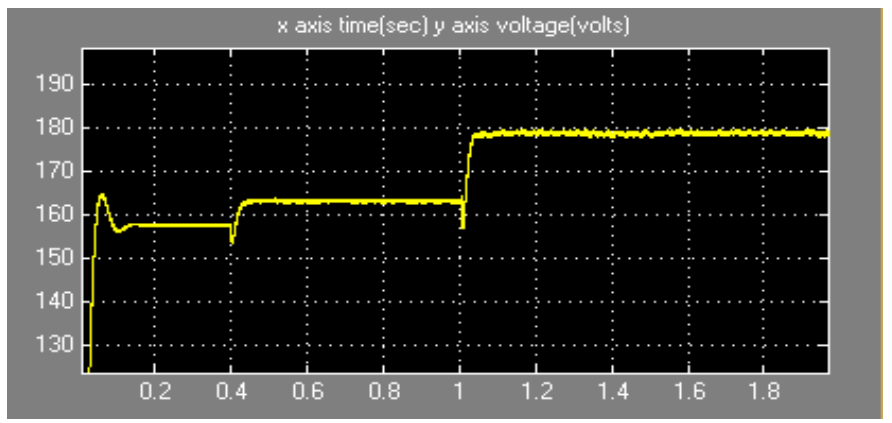

Fig. 4. Output voltage without PI Controller

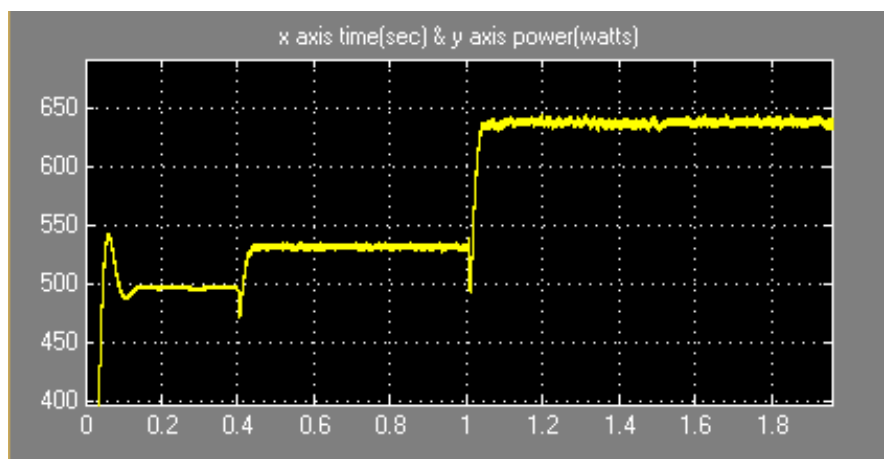

Fig. 5. Output power without PI Controller

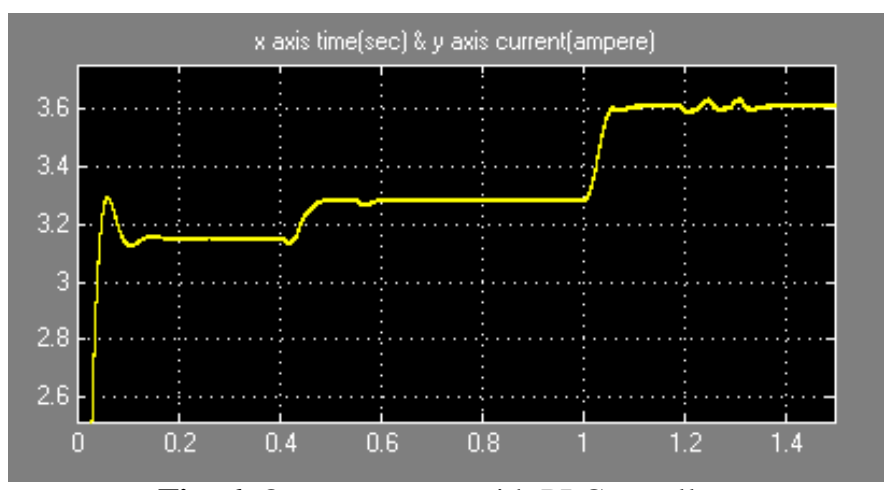

Fig. 6. Output current with PI Controller

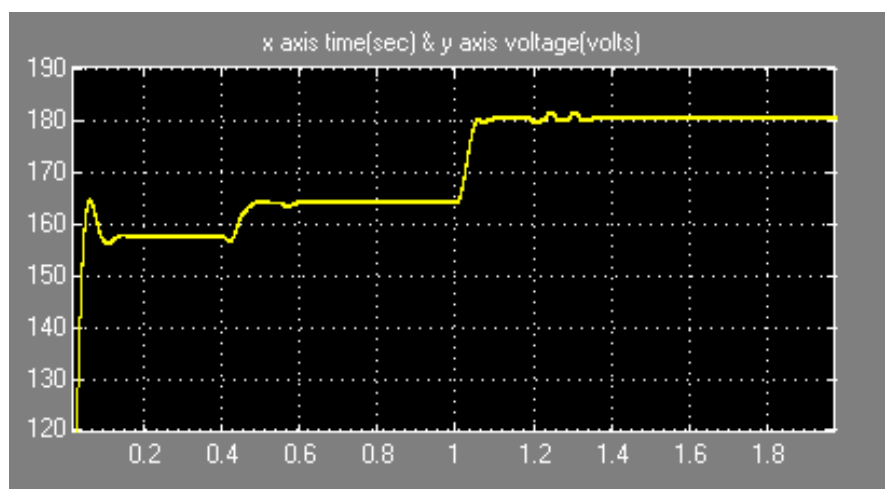

Fig. 7. Output voltage with PI Controller

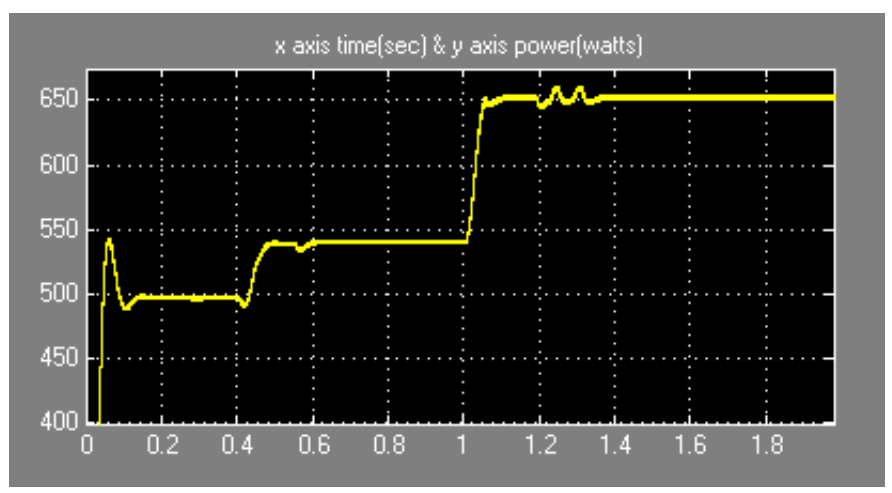

Fig. 8. Output power with PI Controller

\section{CONCLUSION}

The usage of energy from PV panels is very intensive and soon it will become extremely important in finding solutions to energy and environmental problems. In this context this paper concerns the use of MPPT techniques because of its importance in extracting the maximum power available in PV. Among the methods evaluated, the incremental conductance MPPT method is presented as a good solution regarding higher speed, reduced and smaller ripple voltage in steady state, good transient performance, and medium complexity of implementation; however, it is dependent on the PV characteristics. It is noted that the modified $\mathrm{P} \& \mathrm{O}$, incremental conductance based on PID for standalone systems, and P\&O based on PID methods also deserve mention as alternatives for outstanding performance, which are independent from the type/manufacturer of the PV panel, with the incremental conductance based on PID having the best performance even in the face of more realistic daily power profiles and also presenting very good transient performance. However, it is not easy to perform division functions, and in this case, the digital implementation is desirable.

\section{REFERENCES}

[1] V. Salas, M. J. Manzanas, A. Lazaro, A. Barrado, and J. Pierik, "The Control Strategies for Photovoltaic Regulators Applied to Stand-alone Systems," IEEE.,2002, pp. 32743279.

[2] Mohan Kolhe, "Techno-Economic Optimum Sizing of a Stand-Alone Solar Photovoltaic System," IEEE Transactions on Energy Conversion, vol. 24, no. 2, pp. 511-519. 
[3] Roger Gules, Juliano De Pellegrin Pacheco , HélioLeães Hey andJohninsonImhoff "A Maximum Power Point Tracking System With Parallel Connection for PV Stand-Alone Applications," IEEE Transactions on Industrial Electronics, vol. 55, no. 7, pp. 2674-2683.

[4] A. Ellis, D. Schoenwald, J. Hawkins, S. Willard, and B.Arellano, "PV output smoothing with energy storage," 38th IEEE Photovoltaic Specialists Conference., 2012, pp. 1523 1528.

[5] DipankarDebnath, and Kishore Chatterjee, "A Buck-Boost Integrated Full Bridge Inverter for Solar Photovoltaic Based Standalone System," IEEE ,2013, pp. 2867 - 2872.

[6] A. Mani, Hand Book of Solar Radiation Data for India, 1980. New Delhi, India: Allied Publishers Private Limited, 1981.

[7] S. G. Tesfahunegn, O. Ulleberg, T.M. Undeland and P.J.S. Vie, "A Simplified battery charge controller for safety and increased utilization in standalone PV applications". IEEE, 2011,pp. 137-144.

[8] W. Xiao, W. G. Dunford, and A. Capel, "A novel modeling method for photovoltaic cells," in Proc. IEEE 35th Annu. Power Electron. Spec. Conf. (PESC), 2004, vol. 3, pp. 1950-1956.

[9] E. Koutroulis, K. Kalaitzakis, and V. Tzitzilonis. (2008). Development of a FPGA-based system for real-time simulation of photovoltaic modules, Microelectron. J. [Online].

[10] G. E. Ahmad, H. M. S. Hussein, and H. H. El-Ghetany, "Theoretical analysis and experimental verification of PV modules," Renewable Energy, vol. 28, no. 8, pp. 1159-1168, 2003.
[11] G. Walker, "Evaluating MPPT converter topologies using a matlab PV model," J. Elect. Electron. Eng., Australia, vol. 21, no. 1, pp. 45-55, 2001.

[12] M. Veerachary, "PSIM circuit-oriented simulator model for the nonlinear photovoltaic sources," IEEE Trans. Aerosp. Electron. Syst., vol. 42, no. 2, pp. 735-740, Apr. 2006.

[13] R. Sharma, Anurag, " Load Forecasting using ANFIS A Review", International Journal of Research and Development in Applied Science and Engineering, Volume 20, Issue 1, 2020.

[14] Anurag, R. Sharma, " Load Forecasting by using ANFIS", International Journal of Research and Development in Applied Science and Engineering, Volume 20, Issue 1, 2020.

[15] R. Sharma, Anurag, " Detect Skin Defects by Modern Image Segmentation Approach, Volume 20, Issue 1, 2020.

[16] Anurag, R. Sharma, " Modern Trends on Image Segmentation for Data Analysis- A Review", International Journal of Research and Development in Applied Science and Engineering, Volume 20, Issue 1, 2020.

[17] Young Soo Jang et. al., "Development of the costeffective, miniaturized vein imaging system with enhanced noise reduction", International Journal of Advanced Trends in Computer Science and Engineering, Volume 8, No.6, November - December 2019.

[18] Irma T. Plata1, et. al., "Development and Testing of Embedded System for Smart Detection and Recognition of Witches' Broom Disease on Cassava Plants using Enhanced Viola-Jones and Template Matching Algorithm", International Journal of Advanced Trends in Computer Science and Engineering, Volume 8, No.6, Volume 8, No.5, September October 2019. 